\title{
Planting tube makes it easy to plant Japanese paperpot planting
}

\section{stock in Finland}
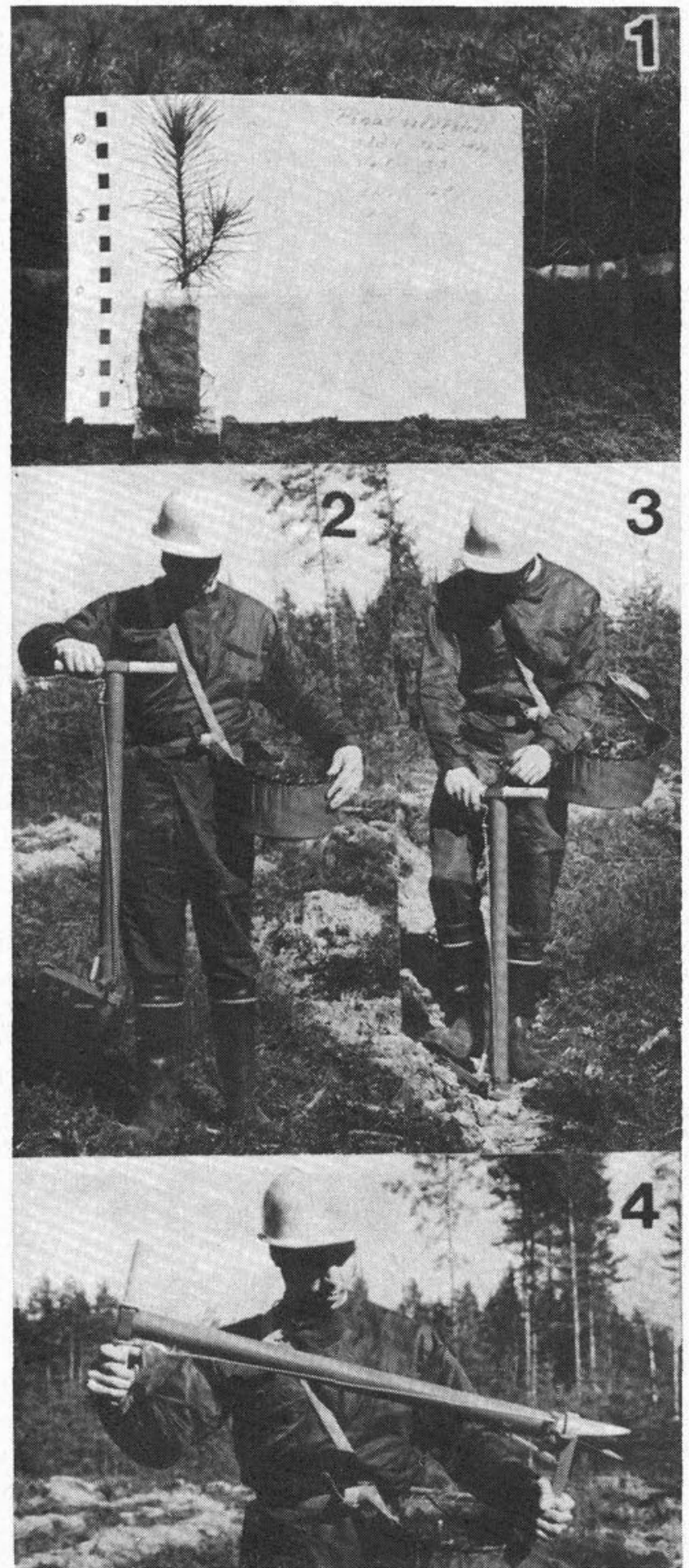

Fig. 1. Scots pine raised in Japanese Paperpots. Seed sown on Feb. 26 and pots transferred on May 13 to unheated plastic house for 2 months and for 1 month without plastic cover. Scale in $\mathrm{cm}$. Fig. 2. Planting tube with blades closed. Fig. 3 . Blades inserted in ground and about to be opened by pressing on pedal. Seedling will then be dropped down tube into hole. Fig. 4. Blades in open position. Note trigger at upper end to release (close) blades.

\section{S.-E. APPELROTH}

The Finnish Forest Research Institute Department of Forest Technology Helsinki, Finland

The use of planting stock raised in Japanese Paperpots (Fig. 1) has increased rapidly in reforestation in Finland. Last year approximately 40 million trees, mainly Scots pine (Pinus silvestris L.) were raised in $\mathrm{FH} 408$ Paperpots ( $35 \mathrm{~mm}$ wide by $75 \mathrm{~mm}$ deep open-ended paper containers), of which half were planted in the forest and half transplanted in nurseries.

A planting tube was developed in the spring of 1970 in Finland to simplify work, and in the summer of that year more than 100 of these tubes, called Pottiputki in Finish, were used. Information on preliminary work studies by the Finnish Forest Research Institute, Department of Forest Technology, on the use of this planting tube is outlined below.

The planting tube is $100 \mathrm{~cm}$ long with an inside diameter of $48 \mathrm{~mm}$; it weighs approximately $3.5 \mathrm{~kg}$. The lower end has steel reinforced blades which are closed when the tube is rammed into the ground (Fig. 2). The correct depth of penetration is maintained by an adjustable hilt. The blades are opened by pressing the pedal with the foot and the potted seedling is then dropped through the tube into the planting hole (Figs. 3 and 4 ). The tube is then lifted up and the soil around the Paperpot firmed by foot $^{1}$. The spring-loaded blades are closed again by pulling the trigger at the upper end of the tube. The operator picks up another seedling from the carrying case on his side while he walks to the next location.

In the pilot studies conducted in north, central and south Finland about 12,000 Paperpot trees were planted by one skilled man with the planting tube. The plants were transported to the regeneration area in styrofoam cases ${ }^{2}$, containing about 200 seedlings each. The planter had a distance of 0 to $150 \mathrm{~m}$ to carry the seedlings before planting.

The planting terrain was classified in three workdifficulty classes: easy, represented by open muskeg, sand heath with some slash, or scarified heathy land; average, represented by ploughed heath as well as unprepared heath with a moderate amount of slash; and difficult, represented by rocky terrain and uneven stony ground with slash which made walking difficult.

The work effort is described in Finland on the basis of pulse rate of the worker, usually as follows: 
Efforts

Very easy work

Easy work

Medium hard work

Hard work

Very hard work

Extraordinarily hard work

Beats/min

below 75

$75-99$

$100-124$

$125-149$

$150-174$

over 175

In the study, the work output of the planter and the work effort measured in heartbeats (pulse rate) ${ }^{3}$ were 462 trees $/ \mathrm{hr}$ and a pulse of 98 beats $/ \mathrm{min}$ in easy terrain, 390 trees $/ \mathrm{hr}$ and 120 beats $/ \mathrm{min}$ in average terrain, and dropping to 312 trees $/ \mathrm{hr}$ and 115 beats $/ \mathrm{min}$ in difficult terrain. Thus planting Paperpot seedling with the planting tube was easy or medium hard work.

A drop in the work effort measured in difficult terrain may have been due to walking more slowly, which at the same time reduced the working pace. In easy conditions on mineral soils, the best daily output was 3,715 seedlings and the working time was $7 \mathrm{hr} 38 \mathrm{~min}$, including a total rest of $43 \mathrm{~min}$ during the work. This was accomplished at 105 heartbeats per minute, demonstrating that there was no undue strain on the planter. On a work site outside this test, where some 60,000 seedlings were planted, planting rate ranged from 2,000 to 3,000 seedlings per day which is similar to Vyse's report ${ }^{4}$ on the latest Walters' gun with bullet seedlings.

The main advantage of the method is that the worker does not have to bend down or bend his knees as in mattock planting or when using a planting stick. The method is very rapid and easier than mattock planting. Moreover, the planting tube is less sensitive to stony or difficult terrain than a mattock. The wedge shape of the blades penetrates coarse sand and gravel better that does the dibble, for example. Since the blades press the soil outward and not down, the bottom end of the planting hole closes when the planting tube is withdrawn.

The main disadvantage of the method is that it can be used only on ploughed or previously scarified areas or on sites where scarification is not needed, such as open muskeg, dry heaths or stony land.

Knowledge about the development of the seedlings planted with the tube is still insufficient and the biological usefulness of this method requires further study. The oldest experiments, however, give hints that there is no reason to assume that Paperpot planting stock planted by this method will not develop as well as those planted with other available tools.

\footnotetext{
It is debatable whether or not the soil must be firmed. Many people think that the hole is too big and that firming must be done. To be safe we do it. Work is slowed down by this additional operation.

${ }^{2}$ Any sturdy, light case can be used for shipping of planting stock. Fish cases of styrofoam are widely used in Finland. ${ }^{3}$ In this pilot test the pulse rate was counted on the wrist and a stopwatch used. Usually in my work studies the rate is measured by attaching a microphone to the chest of the worker and a small radio transmitter on his back. The beats are recorded on a tape recorder from a radio receiver, and the information from the tape is transferred by oscillograph to a paper tape.
}

"VYSE, A.H. 1971. Planting rates increased in British Columbia with new planting gun and bullets. Tree Planters' Notes.

\section{UNIVERSITY OF TORONTO}

Faculty of Forestry

\author{
University Position in
}

\section{Forest Fire Control Science}

Applications are invited for a teaching and research position in Fire Control Science at the Faculty of Forestry, University of Toronto. The successful applicant will be responsible for teaching undergraduate and graduate courses and the supervision of graduate students in appropriate programs of research.

Postgraduate qualification at the Master's or Ph.D. level is required. The area of expertise sought in this position is that of planning, operations research or economics related to fire control problems and environmental protection.

The appointment will be made at a rank and salary commensurate with the qualifications and experience of the successful candidate. An appointment will be made as early as possible in 1972.

Interested and qualified individuals should submit a curriculum vitae and other relevant information, together with the names of three references to the Dean, Faculty of Forestry, University of Toronto, Toronto 5, Canada.

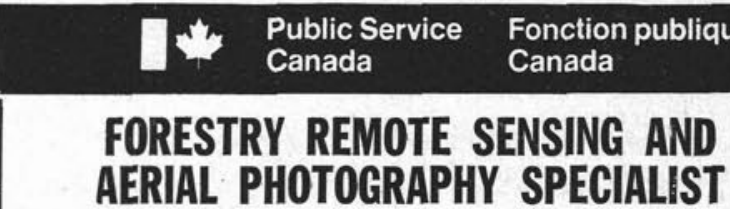

\author{
Salary to $\$ 14,632$ \\ Lands, Forest and Wildlife Service \\ Department of the Environment \\ Ottawa, Ontario
}

Scientist to undertake research and development work in remote sensing and air photography procedures related to forestry projects. The incumbent will select problems and assume the major responsibility for completing the assignments, either as independent projects or as significant elements of a group program. Field work, direction of photo-interpretation and ability to use photo-grammetric equipment, multiband cameras and image enhancement techniques is required.

Application forms (PSC 367-401) or detailed résumés should be forwarded as soon as possible to: -

BIO-PHYSICAL SCIENCES PROGRAM,

PUBLIC SERVICE COMMISSION OF CANADA, TOWER "A", PLACE DE VILLE,

OTTAWA, ONTARIO, K1A OM7.

Please quote 71-110-20 in all correspondence. 